\title{
Global Energy Transition: Redefining India’s Energy Roadmap
}

\author{
Girijesh Pant ${ }^{1, *}$ \\ ${ }^{1}$ Professor Energy Studies, Jawaharlal Nehru University, India \\ *Correspondence: Professor Energy Studies, Jawaharlal Nehru University, India. E-mail: gpant2009@gmail.com
}

Received: May 12, 2017

doi:10.5430/sass.v4n2p36
Accepted: June 26, 2017 Online Published: July 27, 2017

URL: https://doi.org/10.5430/sass.v4n2p36

\begin{abstract}
The onset of transition and transformation in the global energy landscape is disrupting the prevailing energy order, defined by the hydrocarbons. The power dynamics unfolded by global environmental concerns (Paris Agreement) and smart technology is changing the geopolitics by shifting the strategic leverage between energy producers and consumers at various levels: globally, regionally and within the national boundaries. In this strategic shift, the Asian consumers are emerging as critical players both as promoters and spoilers of global energy transition. Since they are the largest consumer of fossil fuel, their compliance with Paris Agreement is going to be vital in meeting the targets and time line. Thus IEA has rightly observed, "Energy developments in India transform the international energy system, and, in turn, India will be increasingly exposed to changes in international markets."

Clearly the Indian roadmap of energy transition is going to be influenced if not determined by its global commitment to meet Intended Nationally Determined Contribution (INDC). The government therefore has all reasons to scale up its targets and execution. However in meeting the targets, it has to address the issue of energy poverty as well. Thus the roadmap has to meet the convergence of minimizing carbon emission meeting the growing energy needs of the poor. This calls for re defining the organizing principle of India's energy policy. Besides ensuring supply security at aggregate level it demands meeting the objectives of energy justice. The transition thus involves not only huge financing (estimated to be 2.5 trillion dollar) and massive technological push but the compatible institutional mechanism and effective system of governance also. Indian energy roadmap has to recalibrate global energy engagement beyond the search of hydrocarbons in consonance with the imperatives of energy transition defined by global and local context.
\end{abstract}

Keywords: energy transition, paris agreement obligations, proactive renewable agenda. solar, the driver, energy poverty, public policy, global solar alliance, distributed energy regime

India ratified Paris Climate Change pact on $2^{\text {nd }}$ October 2016, symbolically on the birthday of Mahatma Gandhi, the father of nation, celebrated as the International Day of Non Violence. This makes India which accounts for 4.5\%of global green house emission, part of the global commitment to keep global temperature below 2 degree Celsius. Consequently, it has resolved to promote cleaner path of development aiming at to reduce emission intensity of its GDP by 33to 35 percent by 2030 from 2005 level, to install 40 percent of power from non fossil fuel by 2030 with the support from international flow of technology and finance. Further, India has accepted to create additional carbon sink of 2.5 to 3 billion tones of CO2equivalent by 2030. The country will be pursuing climate sensitive policies in diverse field of economic activities by creating capacities, promoting research and development and mobilizing resources domestically and globally. (UNFCC.2015)

The Paris Agreement has most significant implications for energy sector because it is the largest source-two third- of green house gas emission. Consequently, changing global energy mix in favour of decarbonising energy resources becomes the strategic choice.IEA observes, "The Paris Agreement is nothing less than a historic milestone for the global energy sector. It will speed up the transformation of the energy sector by accelerating investments in cleaner technologies and energy efficiency." (IEA 2015) Though the Agreement pushing for transition across the globe, countries are drawing their own roadmap in view of their objective conditions and the institutional makeup. The 
drivers and the players including governance will differ contextually, for instance while the industrialized economies are reaching to a stage of peaking demand, the emerging economies are witnessing demand surge for them issue of economic growth remains high on agenda than ecological concerns. However, despite their priorities, the emerging economies are moving towards change in their energy mix. In consonance with global commitment India too is working towards change in its energy mix by setting targets like installing $40 \%$ of power generation capacity from non fossils by 2030. This means enhancing $350 \mathrm{GW}$ of renewable energy capacity from present base of $36 \mathrm{GW}$ accounting for $13 \%$ of total installed capacity of $275 \mathrm{GW}$. (Mittal 2017) Such a leap demands not only huge financing and technology but restructuring of energy systems with a well defined roadmap. It may be added that from the perspective of sustainability, energy transition, "is as much about the democratisation of energy as about greening, industrial leadership and job creation." (R. Sonja van, 2017) The paper is an attempt to look at the ambitions and initiatives taken by India to move on transition path. It argues that being one of largest energy consumer and trapped in energy poverty Indian the trajectory of transition has to be calibrated by synergizing global and the domestic objectives. In Indian energy discourse, it amounts to a major departure by elevating its premise from narrow concern of hydrocarbon supply security to wider canvas of energy poverty, energy justice and sustainability.

\section{Global Energy Market: Transition and Transformation}

Energy transition became part of global agenda primarily due to environmental concerns. The prospective dangers of climate change caused by carbon emission, leading to global warming, impacting global communities diverse ways including threat of existential nature for low lying habitat, that lead to its being made part of global common. It is the magnitude of the impact that the energy transition become a subject of global concern. This was further amplified by the UN declaration of decade of sustainable development for all. According to Energy Transition Commission, there are two options to cut down energy emission namely decarbonising energy supply by enhancing the share of zero carbon sources of energy like renewable. This means changing the energy mix by intervention. The second to to reduce energy demand by efficiency. (Energy Commission 2016) Feasibility of both options depends upon the technological breakthrough. The energy market today is having that breakthrough both in terms of possibilities of beginning of the end of fossil fuel domination in global energy mix and the peaking of energy demand. Thus it can be argued that the push from global commitment and technological changes are defining the pace and trajectory of energy transition at global, national and local level. However unlike the past the present transition is significantly visualized in the larger frame of sustainable energy for all. The terms of reference of transition thus is extended to "just transition" (Jakob 2016) or fair and equitable transition. It is "purposive" hence it demands corresponding public policy support. (Thijs Van de Graaf 2016)

While in the past, transition processes carried with them the elements of disruption in facilitating the progress of the fuel substitution, the present transition is not only driving it at beginning of the end of oil thereby promoting substitute but also encouraging the decoupling energy and growth defined in terms of carbon emission. According to IEA, "Global emissions of carbon dioxide stood at 32.1 billion tonnes in 2015, having remained essentially flat since 2013. The IEA preliminary data suggest that electricity generated by renewables played a critical role, having accounted for around $90 \%$ of new electricity generation in 2015 ; wind alone produced more than half of new electricity generation. In parallel, the global economy continued to grow by more than $3 \%$, offering further evidence that the link between economic growth and emissions growth is weakening." (IEA, 2016).

The peaking of the demand is commented upon by diverse studies. Mackenzie report observes that the oil demand growth going to be flattened to $0.4 \%$ by 2050 . World Energy Council makes more alarming prognosis stating that "Per capita energy demand will peak before 2030, --- This is in stark contrast to historic growth levels, which have seen global demand for energy more than double since 1970. Technological innovation, government policies and lower growth expectations will have a significant impact on the sector in the coming decades." (world Energy Council, 2017) Royal Dutch Shell estimates suggest driven by efficiency and substitution the peak may be possible in next 5 and 15 years. (Katakey, 2017). Michael Liebreich, founder of Bloomberg New Energy Finance, predicts a peak in 2025 and decline in the 2030s. Clearly diverse assessments are converging to point out that the global economy is moving to an energy path where oil will remain the vital player but not with the strategic premium that it has been enjoying over the years. Clearly this changes the very premise of energy geopolitics.

The technological breakthrough is not confined to fuel substitution only. It is likely to transform the organizing principles of the energy market. The prospects of digitalization of energy is expected to bring fundamental changes in global energy systems. It is argued that "the combination of the five S's: software, semiconductors, sensors, solar and storage" is driving the emerging energy revolution which places people to the centre of the energy system. (Reid, 
2016) World Economic Forum too share the prognosis, "The digital transformation of energy systems - smart meters, energy management systems, automated demand response or microgrids - could also help people everywhere access a reliable and affordable source of energy. Two-way communication between energy producers and consumers, as well as the increasing number of prosumers - those who both produce and consume energy - means that distributed energy resources can be dispatched to those areas that need it the most. That could include areas encountering supply shortages and grid stability issues, or those where renewable resources provide only an intermittent energy supply." (WEF2016) The transformational changes are revising producer-consumer relationship-prosumer.

Though the twin processes of transition and transformation are technological driven, their trajectory varies contextually. While transition is happening globally, the transformation is more visible in the western economies." (Germany), farmers and private individuals own more than 50 percent of the solar output in the country.-----Over the course of a full week between the 3rd of May 2016 and the 9th of May 2016, UK's solar panels where generating more electricity from the sun than coal. It is thought to be the first time the UK has been without electricity from coal since the world's first centralised public coal-fired generator opened at Holborn Viaduct in London, in 1882." (Rick, 2016) The energy poor countries of Asia and Africa have yet to make access of energy to bottom of the pyramid estimated to on be 1.2 billion hence have limited option to to make critical departure from carbon based growth. Yet given their affirmation to Paris Agreement, the later too have to calibrate transition to low carbon regime by changing their energy mix. This means in short to medium time term, the global energy market is going to be segmented between two energy regimes, the transformative regime where oil demand will be peaking and digitalization is redesigning the energy architecture and the market where due to energy poverty hydrocarbon remains principal energy supplier but being substituted incrementally by transition processes. However the transition regime, being part of the global is impacted by the pace of developments in transformational regime.

Though technological driven, the twin processes of transition and transformation are not linear in nature, the ecosystem plays equally defining role in their progression or regression. It is not limited to substituting sources of energy but a more radical shift in ecosystem. This means crafting of an enabling regime to promote human, technical, financial, social, organizational, and institutional capacities, compatible for transition and transformation. In the market, where transition towards low carbon systems has to be coexisted with prevailing system, the structural rigidities and preponderance of vested interest demand a huge intervention by the state. Thus, the public policy becomes vital to initiate a road map of transition process where the diverse stake holders perceive the possibilities of gain. The significance of the state intervention in regression is now witnessed in the USA. President Trump's energy policy-America First Energy Plan, not only has restricted the scope of energy transition but has reversed it by placing US economy recovery on the strength of hydrocarbons. The premise is that the USA has unexplored hydrocarbon reserves, those are needed to be harnessed to create 'half million' jobs. Though the coal does get reprieve in US energy basket, the structural shift in energy sector would not allow the President of USA to derail or divert the processes set in by transition and transformation. (ERI, 2017) It is argued that "economics and technological advances are bound to shape the country's energy landscape despite Mr. Trump's very different blueprint. ---utilities (not) going back to investing in coal because they have already reduced their infrastructure and they already have commitments geared toward natural gas," (Kraus, 2017). In the context of promoting transition the state policy has role to address the issue of countries trapped in the energy poverty and see the possibilities of access alon gwith those who need to shift their consumption to more energy efficiency mode. It is imperative that the distribution of cost and gains incurred in transition and transformation is balanced by the principle of energy justice. This means transition and transformation need to push for correcting the prevailing energy injustices of highly centralized energy system. In other word factoring energy justice impinges upon the organizational structure of the energy regime. It also raises the issue of ownership and distribution of energy system. Some leading questions stemming out from the transition to be addressed include, what is the proposed organizing principle of harnessing energy from the resource? Whether and how carbon based regime can address the issue of injustice? How renewable could address the issue of energy justice. The transition trajectory in the countries where transformation is on anvil, shows a strong shift in favour of renewable in decentralized setting. In "Germany, citizen cooperatives have long been investing in the production of renewable energies and some are now looking at how to buy back the energy grid from the energy companies.---- In France, Spain, Croatia and even Greece citizens have started to invest in renewable energy cooperatives." (EASME, 2015). It is argued that with renewable gaining share in the energy mix particularly in the power sector, distributed generation systems are going to play vital role in addressing the issue of energy poverty by providing sustainable energy resources. The sustainability lies in its decentralizing nature. It is significant that the cost of decentralized energy technologies are falling. "Energy distribution does not necessarily need to be through major power plants and large grids. It can be more decentralised. That's a major change that might have an even 
bigger impact on the developing than developed world because it makes investments much lower to build up a functioning energy system." (Carlson, 2016) Thus while is some market structural change is reflecting more in terms of transition than transformation in others the market is reaching at the thresh hold of transformation. India is emerging economy with highly skewed energy market. Its leading position in global energy market makes it imperative to accelerate the twin processes of transition and the transformation simultaneously.

\section{India's Energy Transition: The Text of the Context}

The text of India's energy transition is being scripted by the compelling, to some extent competing imperatives of energy supply security and its environmental ramifications. Its transition to renewable has potentials to secure its vulnerabilities but the growing imbalance between demand and supply does restrict the pace of very transition process. The third largest economy in the world, India faces acute incidence of energy poverty. IEA outlines the leading trends having bearing on Indian energy roadmap. (WEO, 2015)

- India is set to contribute more than any other country to the projected rise in global energy demand, around one-quarter of the total: even so, energy demand per capita in 2040 is still $40 \%$ below the world average

- India's urbanisation is a key driver of energy trends: an additional 315 million people - almost the population of the United States today - are expected to live in India's cities by 2040

- India's need for new infrastructure underlies strong demand for energy-intensive goods, while the rising level of vehicle ownership keeps transport demand on an even steeper upward curve.

- India's power system needs to almost quadruple in size by 2040 to catch up and keep pace with electricity demand that - boosted by rising incomes and new connections to the grid - increases at almost $5 \%$ per year

- Over $50 \%$ of new generation capacity to 2040 comes from renewables and nuclear, while new coal-fired plants in India represent nearly half of the net coal capacity added worldwide

- A large expansion of coal output makes India the second-largest coal producer in the world, but rising demand also means that India becomes, before 2020, the world's largest coal importer, overtaking Japan, the European Union and China

- Production of oil and gas falls well behind the growth in demand: India's reliance on oil imports rises above $90 \%$ by 2040 , requiring constant vigilance as to the implications for energy security.

- Putting manufacturing at the heart of India's growth model means a large rise in the energy needed to fuel India's development.

- India requires a cumulative $\$ 2.8$ trillion in investment in energy supply in our main scenario, three-quarters of which goes to the power sector, and a further $\$ 0.8$ trillion to improve energy efficiency.

The above set of observation points to three leading dimensions of India energy future, first given its growth momentum, India has high stakes in global energy market hence it has to position itself to protect and promote its interest. Second, its energy security concerns no more remain limited to hydrocarbon supply but move to larger resource bases with growing thrust on renewable. Thirdly, the political economy of electoral polity and inclusive growth necessitate to revisit its energy governance architecture including, institutions and policies. The imperatives of greater engagement with global energy market demands, India to calibrate its foreign energy policy to the emerging trends in global energy market. India's energy mix is dominated by hydrocarbons and will continue to be so in near future. Global hydrocarbon market thus remains a critical factor in its global positioning. In the global hydrocarbon market, oil segment is undergoing structural transformation. The growing profile of USA as swing player replacing Saudi Arabia has totally altered the oil geopolitics. Further the peaking of oil demand in industrialized countries has necessitated the oil exporters to look east. Asian energy market is dominated China, India and Japan and Korea though ASEAN too is looking for oil imports. The third largest importer of oil, Indian import demand is expected to be $7.2 \mathrm{mb} / \mathrm{d}$ in 2040 next to China. What is changing the balance is the arrival of many new suppliers, giving India, for that matter any oil importing country to make choice by factoring economics and security parameter. Significantly the American decision to lift oil exports and the energy policy of President Trump add new elements of competition in the market. Reportedly "U.S. crude exports to countries other than Canada soared to more than 350,000 bpd in May, less than six months after Washington lifted a four-decade ban on shipments abroad. Including Canada, U.S. exports have doubled in the past two years to almost 700,000 bopd. China 
and Japan are now regular importers of U.S. crude, with occasional purchases from South Korea, India and Singapore." (World Oil, 216). President Trump's intent to retrieve space for US oil no doubt adds to strategic shift in favour of oil consumers. The point made here is that with supply side of the oil market is more diversified and competitive, Indian position despite high dependence is relatively more secured. Moreover, with revised oil exploration policy, India aims to cut down its oil dependence by $10 \%$ by 2022. (The Economic Times 2017). In the Indian energy mix, natural gas is expected to be the bridge fuel. The country is aiming to move towards gas based energy systems as part of its strategy to clean fuel regime. Its share in energy mix is expected to move from $6.5 \%$ to $15 \%$. The domestic availability of gas has been more speculative than substantive. In fact it has been stagnant, even went down by $5 \%$ in2015.Indian initiatives to have access to gas from international pipelines have not been successful and the prospects are not bright due to geopolitical reasons. Hence LNG becomes the alternative. With a view to transit to gas based economy, India is creating capacities domestically and exploring ties with gas exporting countries. Estimates are that Indian LNG import will go up from 15million tones to 50million tons in 2030. It imports LNG in terms of long, short and spot basis. India imports LNG from eleven countries. Among the important suppliers are Qatar (61\%), Nigeria (14.7\%) Australia, USA, Russia. (Balyan, 2013) Besides India has been active in spot market, it is reported that India proactively negotiated deals during glut in the market (Williams, 2016). Apparently, India has stakes in the global LNG market.

Centrality of coal in India's energy mix, accounting $44 \%$ of it, impedes the pace of transition. India is richly endowed with coal reserves and is the third largest producer and consumer of it. The growing demand of power sector has even compelled it to import coal. Recognizing the inevitability of coal in Indian energy system, India is actively promoting clean coal technology to improve its quality including the ash content by international collaboration. The thermal power plants are being upgraded with super critical and ultra super critical technology. Since the local R\&D infrastructure is not very strong, India is looking for global collaboration proactively to meet its carbon emission pledge. Moving to clean coal technology regime is the commitment of India to Paris Agreement.

It is clear that to address its energy security concerns India has little choice but be atively engaged with global hydrocarbon market. Unlike the past, the market is more diversified with more options. Technology is changing the geopolitical imperatives hence supply security in terms of volume is not goung to be major concern. But as emerging economy, its forein energy policy has to be dynamic and caliberated with new realities. The environmental concerns makes it obligatory that its policy should move towards looking for energy in non hydrocarbon sectors. In the past, India did try for nuclear energy with some success and renewable not so successfully in the past. It was during oil price rise in the seventies and the concern for energy security in nineties that India pushed for nonfossil fuel organically by establishing Ministry of Non Conventional Energy Sources in 1992 which was later in 2006 was re-christented as the Ministry of New and Renewable Energy.However high cost and inadequate technological support restricted their growth. It is with the technologcal breakthroughs and the cutting down of the cost that non fossil fuel became commercially possibble substitute. India's engagement with global climate negotiation gave further filip to Indian inititives however it was the signing of the Paris agreement that has changed the Indian narrative and approach. It may be mentioned here that in contrast to hydrocarbon geology, India's potential renewable are enormous, if suessfuly harnessed, it could make India energy independent. Recent estimates indicate that India's solar potential is greater than $10,000 \mathrm{GW}$ and its wind potential could be higher than 2,000 GW. With a view to harness the potential, India is drawing a road map to transit to clean energy regime.

\section{Transition Roadmap: Initiatives, Issues and Challenges}

The Paris Agreement, could be called game changer in visualizing India's energy future hence in making of energy regime. India is setting targets, taking initiatives, redefining issues and rewriting the script of its energy policy. NITI Ayog has developed future energy scenario with reference to 2047 when India completes hundred years of its independence. According to Ayog, a new energy policy is being drafted making departure from earlier policy frame, "In this policy we are going to give a lot more emphasis on solar energy as the cost of electricity from solar has come down drastically. Natural gas will also get due importance," --- the policy will also try to address air quality concerns. However, the concerns addressed will be specific to India and not just air quality concerns being talked about across the world. ---Another key feature in the energy policy will be the government's attempt to provide universal electricity and provision of clean cooking fuel. When the erstwhile Planning Commission framed its energy policy, around 37 per cent of the country's population did not have electricity and around 75 per cent of the people used solid fuel for cooking. Therefore, these two areas were not addressed by the energy policy of the Planning Commission." (The Hindu, 2016). Seemingly India is anchoring its transition on renewable to respond its global 
commitment to climate change and expanding its resource base to meet the challenges of energy poverty. Along with achieving the numbers, equally important in Indian strategy is to meet the objectives of just transition. Synergizing just transition in low carbon economy raises new issues of political economy namely, what are the organising principles, who sets the terms of transition and for whom. It also poses questions about 'the role of actors, interests and institutions in the energy sector." (Newell, 2014) This brings into debate the issue of political economy ie who are the players, what are the organizational rules, thus what is the road map. These are central concerns because, India is estimated to be among the top five green energy market in the globe in 2015 and market seemingly has no concern for being promoter of just energy economy.

Indian has targeted 175 giga watts power generation from renewable by 2022 of which $100 \mathrm{GW}$ would be from solar power, $60 \mathrm{GW}$ from wind, $10 \mathrm{GW}$ from biomass and $5 \mathrm{GW}$ from small hydro power. According to government estimates it would mean investment of $\$ 89.88$ billion $(600,000$ crore) at the rate of Rs 6 crore per MW at the prevailing rate. Such a huge investment cannot come from state alone. The Indian government is banking heavily on private financing both from India and abroad. It is pitching for \$200 billion investment from India and abroad. According to government sources about three hundred global and local companies have expressed intent to be engaged with renewable power investing \$310-350 billion in coming ten years. (IBEF, 2017) Some of the leading global companies looking for investment in Indian market include, OAO Rosneft (Russia), First Solar (USA), Trina Solar (China). (PTI, 2015)

NITI Aayog, has spelled out the roadmap for renewable by identifying “... RE to be main occupants of the "house" and then work out the rest of the system around RE, essentially, because RE is the future?" Its salient points include the following: (Niti Aayog 2015)

- Treat RE as a resource of national and strategic importance

- Mandate RE as a significant component of the power sector

- Take an integrated approach to power sector planning, including generation, transmission, and distribution

- Make buyers indifferent between conventional and RE resources until grid parity is achieved

- Give small-scale/distributed RE, close to end users, priority equal to large-scale/centralized

The report recommends incremental intervention staggered in stages. In the first stage it calls for minimization of risk perception regarding investor's return expectation. This has to be followed by availability of low cost finance. In third stage central-government entity (e.g. IREDA, PFC) to pool various sources of funds from domestic as well as international sources. The funds could be administered and managed to lend debt (and even part equity, if possible) at lower interest rates. The report also underlines the need to upgrade and integration of grid system. One of the problem that India faces is of uneven distribution of power which due a greater extent has been due to limitation of grids to reach to remote areas. The report therefore rightly underlines the importance of off grid energy system. It recommends:

- Immediately providing stand-alone off-grid systems in remote rural areas for home lighting and running other basic appliances. Over time, these systems could play the same role as that of rooftop systems in urban areas.

- In parallel, developing district and block-level plans for providing electricity through deployment of micro-grids or mini-grids using RE resources. (Niti Aayog, 2015)

The imperatives of reaching targets thereby mobilization of fund, India as observed above is visualizing proactive role of the private players. It is responding to their concerns by making enabling policy changes. The outreach initiatives to investors, are indicative of the policy thrust on promoting market based business model. However, from the perspective of accessibility mere generation of capacities would not address the concern of energy poverty. It is equally critical that renewal transition does not lead to uneven distribution in fact corrects the inequality which hydrocarbon based energy system has created in India. This brings into debate the nature of distribution system. Whether it is premised on centralised grid model or has space for off grid system as well. The point made here is that unlike the hydrocarbon based system where the distribution logistics requires highly centralised system, renewable energy could be produced at local level with off or mini grid system. However, the possibilities of mainstreaming decentralizing model may demand change from utilities in their prevailing business model because, "Some of their most profitable customers will reduce their regular power consumption from the central grid in favor of locally produced power. These customers may still depend on the central grid for their emergency or peak use, so utilities will have to maintain their costly infrastructure and power-generating capabilities even as revenues from consumption decline. In many markets, 
utilities are working with regulators to adapt to this structural change by promoting a pricing model based more on connectivity and capacity and less on usage." (Brief, 2013) It is argued that decentralized energy system could turn out to be cost effective by discounting the possibility of leakage besides the cost of long distance transmission. The point is that with renewable energy coming into mainstream, the carbon energy system too needs to calibrate its business model more so when decentralising model promises more jobs and local empowerment of local habitat including economy as illustrated by episodic experiences from developing and even developed countries like the USA.

Apparently, India is visualizing, the construct of its roadmap largely supported by private players, global financing and technology. It is also influenced by the business model where the state plays a role but more of facilitator of market which is promoter of centralized system like the ultra mega size solar park. This could be further inferred from the limited role visualized for off grid or mini grids in its transition strategy. The leading role of private players can be illustrated by the fact that they have proposed to develop $190 \mathrm{GW}$ of renewable projects, while state owned entities are expected to be developing $18 \mathrm{GW}$, foreign investor are expected to develop 58GW. (PWC, 2015). Mobilizing funds by creating policy regime thus has acquired priority in Indian scheme. Indian government is going a big way to finance renewable by promoting tax free green bonds. State companies are expected raise Rs 5000 crore by such bonds. (Bhaskar, 2015) So far most of such financing has come from the government entities and banks including from private sector but domestic bond and capital market has yet to show their interest. The government has also allowed $100 \%$ ownership for foreign companies to attract technological support. It can be argued that India is pitching its energy initiatives to register its presence as the leading nation on global energy map. This is best illustrated by its initiative to established International Solar Alliance as multilateral platform to promote solar energy across the globe. It is argued that in the backdrop of sustainable energy need, countries located between Tropic of Cancer and Tropic of Capricorn are so richly endowed with solar radiation that they could move away from dependence on carbon energy provided they could harness it. The Alliance is a joint effort from India and France to bring about 129 countries on a common platform. The platform aims at to bring these countries to be engaged on cooperative and collaborative mode in developing technology at cost effective rate. The idea was given a concrete profile in the sideline of Marrakesh meeting in November 2016 where reportedly more than 20 countries signed a framework of agreement, making it intergovernmental body registered under UN charter. The objective of the Alliance are following: (UNFC)

- promote solar technologies, new business models and investment in the solar sector to enhance prosperity

- formulate projects and programmes to promote solar applications

- develop innovative financial mechanisms to reduce cost of capital

- build a common knowledge e-Portal

- facilitate capacity building for promotion and absorption of solar technologies and R\&D among member countries.

India is pitching its transition beyond the national turf. It is projected in the wider frame of common but differentiated global responsibility. Indian profiling of its renewable objectives have received global endorsement. "India's plans to virtually triple the share of renewable energy by 2030 will both transform the country's energy supply and have far-reaching global implications in the fight against climate change," said Kim. (World Bank) ----- The World Bank Group will do all it can to help India meet its ambitious targets, especially around scaling up solar energy." (World Bank 2016)

The proactive role of the state in pushing energy transition is well evident its policy inititives like the fiscal incentives and ease of doing business. The former includes, accelerated depreciation, concessional custom duty, excise duty exemption, income tax holidays for ten tears etc Among the critical policy intervention is the provosion of Renewable Purchase Obligation,(RPO), "prescribing purchase of solar energy to promote renewable energy with an aim to reach upto $8 \%$ of toal electricity consumption by March,2022." (Ministry of New Renewable Energy. 2017) With a view to ease the doing business, renewable is re classified as "white category which exempts theses projects to exempt from seeking environment clearance." (Ministry of New Renewable Energy. 2017)

While the urban bias of Indian energy transition is visible and possibly explained by the power dynamics, yet the imperatives of electoral politics has made rural electrification an important deliverable. Thus, the transition regime also talks about decentralizing mode of rural electrification. The prevailing view seems to look at DRE as complementary to It is even argued that, "There is enough evidence to move beyond the distinction between grid power and off-grid power, and to develop an integrated system where cross cutting, innovative solutions work together and help achieve the ultimate goal of energy access. There is an urgent need for a paradigm shift towards considering DRE solutions as complementary to the grid, and centralized energy providers. not in competition with it. Energy access, being the 
immediate focus, has engaged all stakeholders from the central and state governments, investors, to private developers and consumers. Each stakeholder now needs to understand the importance of an integrated intervention strategy at both the tail-end and the generation side, along with a one track focus on developing and promoting the right solutions for the right applications." (Gupta, 2016) Apparently, the challenge that India faces in defining its energy inclusive transition strategy is to synergize the two distinct trajectories though not conflicting but possibly competing, given the power dynamics, where urban bias is very clearly visible. Further it is argued that Indian approach has yet to spell out the institutional frame work to promote innovative ecosystem that provides sense of participation among the local stakeholders or communities. (Sarangi, 2012) The approach appears to to be to take leaf from success stories hoping those might trigger the pace of transition. The experience from other countries suggest that such stand alone cases need to be converted into a network to push the processes from bottom up. In this the role of intermediaries have been found to be vital. (Schoffelen, 2015)

Conclusion: One of the largest energy consumer, energy transition of India is critical to meet the targets of Paris Agreement. It is equally necessary to meet Indian energy needs. No wonder that besides being driven by proactive public policy, it has drawn attention and interest of global players be the multilateral agencies or the corporate. Finance and technology are vital for its implementation so is the governance. The Indian state is creating enabling ecosystem. to Apparently in doing so, the organizing principle have not been suitably modified and crafted. It can be argued that its orientation is more of linear progression. The approach seemingly remains to be tilted in favour of grid extension over decentralized distributed generation. As observed earlier the findings show that the grid based centralized system not only faces the constraints of high cost and distributional losses but also fails to address the issue of skewed power distribution specially in rural setting. (Khandeke, 2012) Further the studies have also observed that the potentials of mini grades in rural India have been restrained by the absence of private investment. It is also observed "that mini-grids based on solar PV power and storage are more economical than incumbent energy services available to households without central grid connection." (Khandeke, 2012) Moreover it is also found out that "the threat of central grid extension is the gateway barrier preventing mini-grid development in India." (Khandeke, 2012) Apparently the imperatives of just sustainable energy services demands reconstructing of the ecosystem not in a piecemeal way but in a wider integrated perspective. The political economy of sustainable energy transition clearly makes a compelling case of centrality of energy justice in transition trajectory of India.

\section{References}

Balyan, A.K. (2013). Meeting Demand Challenges of An Emerging LNG Market: India. Retrieved from http://www.gastechnology.org

Bhaskar, U. (2015). India's plan to quadruple its renewable energy production. Retrieved from http://www.livemint.com

Brief, Bain. (2013). Distributed energy: Disrupting the utility business model. Retrieved from http://www.bain.com

Carlson, Peter. Battery breakthrough 5-8 years away. Retrieved from https://tbb.innoenergy.com

Comello. D., Reichelstein S., Stefan J., Reichelstein, Sahoo Anshuman, \& Schmidt Tobias S. (2016). "Enabling Mini-grid Development in Rural India" Working Paper, July, 2016 Stanford Graduate School of Management

EASME. (2015). Spreading the model of renewable energy cooperatives. Retrieved from https://ec.europa.eu/easme/en/news

Elcano Royal Institute. (2017). Trump's Supply-Side Energy Policy and The Low-Carbon Transition - Analysis Retrieved from http://www.eurasiareview.com/20022017

Energy Commission (2016). Pathways from Paris. Retrieved from http://www.energy-transitions.org

Gupta, Deepak. (2016). Leading shift narrative clean energy access India. Shakti foundation.

http://www.worldenergy.org/news.accsed 5-11-2017

IBEF (2017). Power Sector in India. Retrieved from https://www.ibef.org

IEA. (2015). IEA warmly welcomes Paris Agreement.

IEA. (2016). Decoupling of Global Emissions and Economic Growth Confirmed. Retrieved from https://www.iea.org/newsroom/news 
Jakob Michael \& Steckel Jan Christoph. (2016). The Just Energy Transition. WWF.

Katakey, Rakteem. (2016). Shell says oil demand could peak in five years. Retrieved from http://www.independent.co.uk

Khandeke, R S., Samad, H A., Ali, R., \& Barnes, D F. (2012). The impacts of electrification across income and expenditure quantiles vary, with richer households tending to benefit more than poorer ones. In fact, households in the lower two expenditure quantiles (15th and 25 th percentiles) accrue very little (statistically zero). In terms of income, households from all quantiles benefit from electrification; for those in the lowest quantile (15th percentile), the impact is about 26 percent, compared to nearly 46 percent for the richest households (85th percentile). "Who Benefits Most from Rural Electrification? Evidence in India." The Energy Journal vol 35 no 2.

Kraus C., \& Cardwell. D. Policy Shift Helps Coal, but Other Forces May Limit Effect. Retrieved from https://www.nytimes.com/2017/03/28

Ministry of New Renewable Energy. (2017). New and Renewable Energy Sector, Achievements Report.

Mittal, S. (2015). India Aims For 350 GW Renewable Energy Capacity By 2030. Retrieved from https://cleantechnica.com/2015/09/23

Newell, P., Phillips, J., Pueyo, A., Kirumba, E., Ozor, N., \& Urama, K. (2014).The Political economy of Low carbon Economy in Kenya IDS Working Paper 445. http://www.ids.ac.uk/publication20 NITI Aayog,(2015) Govt of India, Report on India's Renewable Electricity Roadmap 2030: Towards Accelerated Renewable Electricity Deployment."21 PTI (2015) India eyes \$200 billion investment in renewable energy. Retrieved from http://www.business-standard.com

PWC. (2015). Renewable-Energy -Transformation. Retrieved from http://www.pwc.in

R. Sonja van. (2017). Exclusive interview/ sneak preview: energy transition architect Claude Turmes tells inside story of EU energy policy. Energy Post 24-2-2017.

Reid, G. (2016). Digitalisation of Energy and Its Implication. Retrieved from http://energyandcarbon.com

Rick, Torben. (2016). Energy Industry on The Brink of Disruption. Retrieved from https://www.torbenrick.eu

Sarangi, G K., \& Mishra, A. (2012). Mainstreaming Off-grid Renewable Energy Systems in India: An Integrated Approach. TERI University.

Schoffelen, Jorn. (2015). How to support bottom-up energy transitions? A strategic niche management analysis of intermediary organizations facilitating community energy development in the Netherlands. Thesis submitted in partial fulfillment of the MSc. Climate studies at Wageningen UR, The Netherlands.

The Economic Times. (2017). India announces new licensing policy to boost oil output. Retrieved from http://economictimes.com

The Hindu. (2016). NITI Aayog ready with draft national energy policy. Retrieved from http://www.thehindubusinessline.com

Thijs Van de Graaf, Benjamin K., Sovacool Arunabha Ghosh, Florian Kern \& Michael T. Klare. (2016). The International Political economy of Energy. Palgrave Macmillon pp.292.

UNFCC, (2015). India's Intended Nationally Determined Contribution: Working Toward Climate Justice. Retrieved from http://www4.unfecc.

UNFCC, International Solar Alliance: Mobilizing US D 1 Trillion for Solar Energy by 2030. Retrieved from http://newsroom.

UNFCC, International Solar Alliance: Mobilizing US D 1 Trillion for Solar Energy by 2030. Retrieved from http://newsroom

UNFCC. (2015). India's Intended Nationally Determined Contribution: Working Toward Climate Justice. Retrieved from http://www4.unfecc

Williams. P. (2016). India Scours Globe for Bargain LNG as Domestic Plants Idle

World Economic Forum. 2016.

World Energy Outlook. (2015). India Energy Outlook, 2015. 
World Oil. (2016). U.S. crude exports competitive to Asia-Pacific, delivered prices show. Retrieved from http://www.worldoil.com/news/2016 